\title{
Creencias sobre los roles del profesor y del estudiante que poseen futuros docentes de inglés en dos universidades chilenas ${ }^{1}$
}

\author{
Beliefs Concerning the Roles of Teacher and Learner Held by Pre-Service \\ Teachers of English from two Chilean Universities
}

\author{
Crenças sobre o rol do professor e o estudante que têm futuros \\ professores de inglês em duas universidades chilenas
}

\author{
Tania Tagle Ochoa ${ }^{2}$ \\ Claudio Díaz Larenas ${ }^{3}$ \\ Paola Alarcón Hernánde $z^{4}$ \\ Lucía Ramos Leiva ${ }^{5}$ \\ Marcela Quintana Lara ${ }^{6}$ \\ Paulo Etchegaray Pezo7
}

\section{Resumen}

Este artículo se deriva de una investigación que tuvo como propósito identificar las creencias sobre los roles del profesor y del estudiante que poseían 24 futuros docentes, los cuales eran parte del programa de formación profesional de pedagogía en inglés en dos universidades chilenas y se encontraban cursando el último año de preparación. Las técnicas consideradas para recolectar información fueron la observación no participante en función de una clase de inglés implementada por los sujetos de estudio, además de una entrevista semiestructurada con recuerdo estimulado sobre su desempeño en el aula. Se realizó análisis de contenido de los datos recolectados con respecto a las entrevistas; se llevó a cabo la codificación y categorización de la información por medio del software de análisis cualitativo Atlas.ti. Los resultados demuestran que los participantes poseen creencias sobre los roles del profesor y del estudiante basadas en una propuesta constructivista y tradicional sobre la enseñanza y el aprendizaje del idioma inglés. Se sugiere que los programas de formación inicial docente consideren estos hallazgos para perfeccionar la preparación de los profesionales de la educación.

Palabras clave

Formación de docentes, creencias, rol del profesor, rol del estudiante, enseñanza de idiomas

Abstract

This article was derived from a research study whose purpose was to identify student teachers' beliefs concerning the teacher's and learner's roles. The participants were 24 subjects enrolled in their last year of professional preparation at English language pedagogy programs offered by two Chilean universities. The techniques used to gather data were non-participant observation concerning an English lesson implemented by the research subjects and a stimulated-recall semi-structured interview focused on their observed teaching performance. A content analysis procedure regarding the interview was employed, using codes and categories provided by qualitative analysis software, Atlas.ti. The results indicate that the participants hold beliefs concerning the teacher's and learner's roles based on a constructivist and traditional approach to teaching and learning English. Initial teacher training programs should consider these findings in order to improve the process of preparation of teaching professionals.

\section{Keywords}

Teacher training, beliefs, teacher's role, learner's role, language teaching

1 Este artículo forma parte del proyecto Fondecyt n. ${ }^{0} 1150889$ titulado "Las dimensiones cognitivas, afectivas y sociales del proceso de planificación de aula y su relación con los desempeños pedagógicos en estudiantes de práctica profesional y profesores nóveles de pedagogía en inglés".

2 Universidad Católica de Temuco, Chile. Correo electrónico: ttagle@uct.cl.

3 Universidad de Concepción, Chile. Correo electrónico: claudiodiaz@udec.cl.

4 Universidad de Concepción, Chile. Correo electrónico: palarco@udec.cl.

5 Universidad Arturo Prat, Iquique, Chile. Correo electrónico: lucia.ramos@unap.cl.

6 Universidad Arturo Prat, Iquique, Chile. Correo electrónico: marcela.quintana@unap.cl.

7 Universidad Católica de Temuco, Chile. Correo electrónico: petchegaray@proyectos.uct.cl. 
Este artigo é derivado de uma pesquisa que visou identificar as crenças sobre o rol do professor e o rol do estudante de 24 futuros professores que faziam parte do programa de formação professional de pedagogia em inglês em duas universidades chilenas e cursavam o último ano de estudos. As técnicas consideradas para recolher a informação foram a observação não participante em função de uma aula de inglês implementada pelos sujeitos de estudo, além de uma entrevista semiestruturada com evocação estimulada sobre seu desempenho na sala de aula. Foi realizada uma análise de conteúdo dos dados obtidos em relação com as entrevistas, levando a cabo a codificação e categorização da informação mediante o software de análise qualitativo ATLAS.ti. Os resultados demonstram que os participantes baseiam suas crenças sobre o rol do professor e do estudante em uma proposta construtivista e tradicional sobre o ensino e a aprendizagem da língua inglesa. Sugere-se que os programas de formação inicial de professores levem em conta esses resultados para aperfeiçoar a preparação dos professionais da educação.

Palavras chave: formação de professores, crenças, rol do professor, rol do estudante, ensino de línguas

Artículo recibido el 22 de noviembre de 2015 y aprobado el 5 de agosto de 2016

\section{Introducción}

Diferentes especialistas plantean la relevancia de identificar cómo se perciben los roles del estudiante y del profesor en el proceso de enseñanza y aprendizaje (véase, por ejemplo, Alarcón, Díaz, Tagle, Ramos y Quintana, 2014; Saban, 2004; Thomas y Beauchamp, 2011). Estos autores coinciden en que lo anterior resulta útil para permitir que los docentes reconozcan y cuestionen su desempeño en el aula y, por consiguiente, perfeccionen su actuar pedagógico.

Las prácticas pedagógicas de los docentes serían influenciadas por sus creencias sobre la enseñanza y el aprendizaje. Al respecto, se sugiere que, en el contexto chileno, las creencias que subyacen a la acción de los profesionales de la educación estarían basadas, frecuentemente, en el denominado paradigma de transmisión de conocimientos y se caracterizarían por concebir el conocimiento como información (Gómez y Guerra, 2012). Estas creencias sobre la enseñanza y el aprendizaje serían de carácter tradicionalista y su propósito principal estaría centrado en favorecer la formación de hábitos o la exposición de contenidos. Lo anterior no dejaría lugar para la implementación de prácticas pedagógicas que busquen la generación de saberes, por parte de los estudiantes, a través de procesos que involucren la maximización de habilidades de pensamiento superior o de la autonomía.

Resulta difícil para los profesionales de la educación modificar sus creencias pedagógicas. Lo anterior se debe a que estas representaciones se encuentran arraigadas e implícitas en la memoria de largo plazo de los docentes, y muchas veces son invisibles a su conciencia (Erkmen, 2014). No obstante, las creencias podrían transformarse si se establecen instancias destinadas a reestructurar las mismas. En este sentido, tanto la práctica pedagógica como la actividad curricular en programas de formación de profesores y los procesos reflexivos asociados contribuirían a este cambio. Desde el punto de vista de Blázquez y Tagle (2010), la práctica docente ayudaría a los estudiantes de pedagogía a modificar sus creencias debido a que las experiencias que esta implica les proveerían oportunidades para que desarrollen la acción profesional $\mathrm{y}$, además, reflexionen sobre esta última.

Buscando transformar las representaciones de los futuros docentes, las universidades chilenas consideradas en este estudio integran en sus itinerarios formativos cursos de práctica progresiva, desde el segundo hasta el cuarto año de preparación profesional, y la práctica profesional en el quinto año. Al ir implementando sus intervenciones en el sistema educativo, los estudiantes de pedagogía reflexionan sobre su desempeño con el apoyo de los docentes que imparten las asignaturas focalizadas en la práctica de la especialidad. En este contexto, se espera que los futuros profesores, en forma progresiva, vayan modificando sus creencias tradicionales por creencias enmarcadas en una propuesta constructivista sobre la enseñanza y el aprendizaje del inglés. El propósito 
de lo anterior es que los estudiantes de pedagogía en inglés integren en su sistema de representaciones pedagógicas una visión en la que predomine el desarrollo de habilidades del idioma extranjero por sobre la replicación o transmisión de contenidos de tipo gramatical, léxico o fonético-fonológico.

Asociado a lo mencionado, el objetivo de esta investigación fue develar las creencias sobre los roles del profesor y del estudiante que poseían futuros docentes de la carrera Pedagogía en Inglés, los cuales cursaban su quinto año de formación en dos universidades chilenas y que se encontraban realizando su práctica pedagógica final en establecimientos educacionales del sur y norte de Chile.

\section{Marco de referencia}

\section{Creencias en la formación de profesores}

Las creencias pedagógicas corresponden a redes complejas de procesamiento que se encuentran almacenadas en la memoria de largo plazo de los profesionales de la educación (Díaz y Solar, 2011). Estas filtrarían el conocimiento de carácter teórico que adquieren los docentes y lo transformarían en un conocimiento práctico, personal y subjetivo, que guiaría las decisiones y formas de desempeñarse dentro del aula.

Se ha estipulado que estudiantes de pedagogía desarrollan y adquieren creencias sobre la enseñanza y el aprendizaje por medio de la observación del desempeño profesional de sus propios docentes en el contexto escolar (véase, por ejemplo, Levin y He, 2008). Relativo a lo anterior, estas representaciones serían difíciles de transformar y actuarían como un marco de referencia en función de cómo los estudiantes comprenden nuevas ideas sobre el aprendizaje y la enseñanza. En este contexto, los futuros docentes replicarían las prácticas pedagógicas de los profesionales de la educación que les impartieron clases.

$\mathrm{Al}$ respecto, se ha señalado que cuando los futuros profesores se integran a programas de formación pedagógica, traen consigo creencias enmarcadas en una visión simplista de la enseñanza y ligada a la transmisión de conocimientos (Wright, 2010). Estas representaciones sobre la enseñanza se asociarían a la implementación de prácticas docentes tradicionalistas.
Creencias sobre los roles del profesor y del estudiante que poseen futuros docentes de inglés en dos universidades chilenas Tania Tagle Ochoa / Claudio Díaz Larenas / Paola Alarcón Hernández / Lucía Ramos Leiva / Marcela Quintana Lara / Paulo Etchegaray Pezo

La modificación de las creencias pedagógicas es un proceso complejo. En este sentido, Díaz, Martínez, Roa y Sanhueza (2010) sostienen que los docentes, al intentar cambiar su sistema de creencias, sufren inseguridad y frustración. Con respecto a lo planteado por estos autores, lo anterior sucedería porque ellos intentarían redefinir su desempeño docente en el marco de representaciones que les serían ajenas, y en consecuencia sería muy complicado considerar como válida toda información opuesta a su visión sobre la enseñanza y el aprendizaje.

En función de procesos de formación profesional, el carácter implícito de las creencias obstaculizaría su transformación por parte de estudiantes de pedagogía (Levin y Wadmany, 2006). Debido a que las creencias serían almacenadas de forma tácita, tratar de reconocerlas, articularlas y explorarlas resultaría un desafío. Este hecho se relacionaría con la perpetuación de prácticas pedagógicas ligadas a un paradigma tradicional de la enseñanza y el aprendizaje.

\section{Aprendizaje en un marco constructivista y tradicional}

Cuando se hace referencia al proceso de aprendizaje desde la propuesta constructivista, se alude a la construcción de significados como elemento principal del proceso de enseñanza-aprendizaje (Coll, 1990). Este proceso ocurriría cuando la persona es capaz de atribuirle un sentido a los contenidos con los que interactúa, es decir, cuando establece relaciones sustantivas con lo que aprende y los conocimientos construidos a partir de sus experiencias de aprendizaje previas (Coll, Onrubia y Mauri, 2008; Falsafi y Coll, 2011). Desde esta perspectiva, el objetivo del aprendizaje no es almacenar la información transmitida ni desarrollar un conjunto de hábitos, sino que se trata de construir o re-construir esquemas o constructos mentales en formas que son exclusivamente significativas para el aprendiz (Ausubel, 2002).

En el caso del aprendizaje del inglés, el proceso de construcción de significados se desarrollaría a través de la exposición al lenguaje en contextos significativos y mediante actividades que favorezcan el desarrollo de las habilidades lingüísticas (comprensión y expresión oral/escrita). En este marco, el estudiante construiría 
conocimientos, estableciendo conexiones entre lo previamente aprendido y las nuevas experiencias a través de una activa participación y autogestión (Pagliaro, 2011).

Por otro lado, desde una perspectiva tradicional, el aprendizaje del idioma se asociaría a la formación de hábitos (Richards y Rodgers, 2014), producto de una ejercitación constante, principalmente, de contenidos lingüísticos relacionados con gramática y vocabulario. En este contexto, el rol desempeñado por el estudiante sería de un carácter básicamente pasivo, actuando como un receptor de la información expuesta por el docente (Arends y Kilcher, 2010; Lippman, 2010; Nilson, 2010).

\section{Enseñanza en un marco constructivista $y$ un marco tradicional}

Desde un punto de vista asociado al paradigma constructivista, no existe una forma específica de enseñar debido a que la preocupación exclusiva de esta práctica social es ayudar a generar el aprendizaje (Williams y Burden, 2001). El aprendizaje es el objetivo de la enseñanza y este, en términos de desarrollo de constructos, es básicamente un proceso diferente para cada individuo (Malderez y Bodóczky, 2002).

En el contexto de una propuesta constructivista sobre la enseñanza de una lengua extranjera, esta se asociaría a la implementación de prácticas pedagógicas focalizadas en el desarrollo de las habilidades lingüísticas, es decir, prácticas basadas en una visión del uso del lenguaje en el proceso de comunicación (Richards, 2006). En este marco, el rol del profesor se relacionaría con generar las condiciones apropiadas para que el aprendizaje se efectúe.

Desde una perspectiva tradicional, la enseñanza del idioma se asociaría a un proceso de transmisión de información, esencialmente de contenidos lingüísticos por medio de la memorización y reproducción (Wheeler, 2013). De acuerdo con Larsen-Freeman y Anderson (2011), esta práctica se basaría en la idea de que el profesor se desempeña como una autoridad en la sala de clases y expositor de contenidos de aprendizaje, tales como aspectos gramaticales e ítems relacionados con vocabulario.

\section{Metodología}

Esta investigación emplea un diseño de investigación de carácter cualitativo. Este tipo de metodología es coherente con el objeto de este estudio ya que las creencias se conectan directamente con las dimensiones cognitiva y afectiva de los sujetos.

El tipo de investigación corresponde a un estudio de caso de naturaleza interpretativa que busca indagar sobre las creencias que posee un grupo de futuros docentes respecto a los roles que ejercen el profesor y el estudiante considerando el proceso de enseñanza y aprendizaje del idioma inglés.

\section{Informantes}

Los participantes del estudio fueron 24 estudiantes de la carrera de Pedagogía en Inglés, los cuales pertenecían a dos universidades nacionales: 10 provenían de una universidad del sur de Chile y 14 de una universidad del norte del país. Todos ellos se encontraban cursando el último año del programa de formación profesional en cada institución. Del total de informantes, 8 eran de sexo masculino y 16 de sexo femenino. Sus edades fluctuaban entre 22 y 27 años.

Como criterio de exclusión se consideró que estos estudiantes no debían haber formado parte de programas de movilidad estudiantil en países de habla inglesa ${ }^{8}$. Lo anterior, para no permear sus creencias con experiencias formativas externas a los procesos de preparación profesional en los que se vieron involucrados en las dos instituciones de educación superior.

\section{Técnica de generación de los datos}

En primer lugar, se empleó la observación no participante. Los investigadores observaron y filmaron una clase de inglés implementada por cada uno de los sujetos de estudio en el contexto de sus prácticas pedagógicas en establecimientos educacionales.

Asimismo, se consideró una entrevista semiestructurada como instrumento de recolección de datos

8 Los estudiantes pueden haber estudiado un semestre en universidad extranjera por beca obtenida a través del Ministerio de Educación de Chile mientras cursan el cuarto o quinto año de estudios en la carrera de Pedagogía en Inglés. 
(véase el protocolo de entrevista en el Anexo 1). El protocolo de esta entrevista se basó en uno utilizado en un estudio previo realizado por los investigadores (Tagle, Díaz, Alarcón, Quintana y Ramos, 2014).

Con el propósito de recolectar información sobre las creencias pedagógicas de los informantes por medio de su discurso oral, la entrevista semiestructurada se complementó con la técnica de recuerdo estimulado. Esta técnica consiste en entrevistar a los participantes de un estudio exponiéndolos a estímulos visuales sobre sus propias acciones. Este procedimiento facilitaría los procesos de reflexión sobre el propio desempeño (Gass y Mackey, 2000). Para realizar lo señalado, de manera simultánea al desarrollo de la entrevista, se presentó a los participantes segmentos de video asociados a las sesiones de clase que ellos implementaron.

\section{Procedimiento}

Se invitó a participar en el estudio, de forma voluntaria, a estudiantes de la carrera de Pedagogía en Inglés, los cuales estuviesen comprometidos con el desarrollo de su práctica profesional final.

Se observó y filmó una sesión de clase de cada participante. Consecutivamente, se desarrolló una entrevista semiestructurada post observación, la cual fue complementada con la técnica de recuerdo estimulado. En el desarrollo de la misma se expuso a los informantes los segmentos de video más representativos en función de las preguntas asociadas a creencias sobre los roles del profesor y del estudiante consideradas en el estudio. Es relevante mencionar que, con el propósito de recolectar información fidedigna por medio del discurso oral de los participantes, la entrevista fue llevada a cabo en español, el cual era su idioma materno. Esta se prolongó por, aproximadamente, 40 minutos.

Una vez que se realizaron las entrevistas, se transcribieron. Para procesar la información recolectada, se empleó el análisis de contenido por medio del software Atlas.ti. A través del uso de este programa computacional, se codificaron los datos y se identificaron los segmentos del discurso de los participantes que estuviesen ligados a los focos de la investigación. Posteriormente, se procedió a organizar la información, se levantaron las categorías y subcategorías en función de "creencias sobre el rol del profesor" y "creencias sobre el rol del estudiante" que poseían los informantes. Lo anterior se llevó a cabo estableciendo relaciones de significado entre los códigos previamente reconocidos.

\section{Resultados}

En función del análisis de las entrevistas, la tabla 1 presenta una síntesis respecto de los resultados considerando el discurso oral de los participantes del estudio. Estos hallazgos fueron agrupados en dos categorías: creencias sobre el rol del profesor y creencias sobre el rol del estudiante.

Tabla 1. Resumen sobre resultados

\begin{tabular}{|l|c|}
\hline \multicolumn{1}{|c|}{ Categorías } & \multicolumn{1}{c|}{ Subcategorías } \\
\hline $\begin{array}{l}\text { Creencias sobre el } \\
\text { rol del profesor }\end{array}$ & $\begin{array}{c}\text { Dimensión profesional } \\
\text { Facilitador del aprendizaje } \\
\text { Transmisor de información } \\
\text { Dimensión personal } \\
\text { Orientador } \\
\text { Figura parental }\end{array}$ \\
\hline Creencias sobre el & $\begin{array}{c}\text { Constructor de } \\
\text { conocimientos } \\
\text { rol del estudiante }\end{array}$ \\
\hline Recente activo de información \\
\hline
\end{tabular}

\section{Creencias sobre el rol del profesor}

La categoría "creencias sobre el rol del profesor de inglés", presentada a través de una red conceptual (véase la figura 1), permite identificar las siguientes subcategorías: dimensión profesional y dimensión personal. 
Figura 1. Red conceptual asociada a creencias sobre el rol del profesor

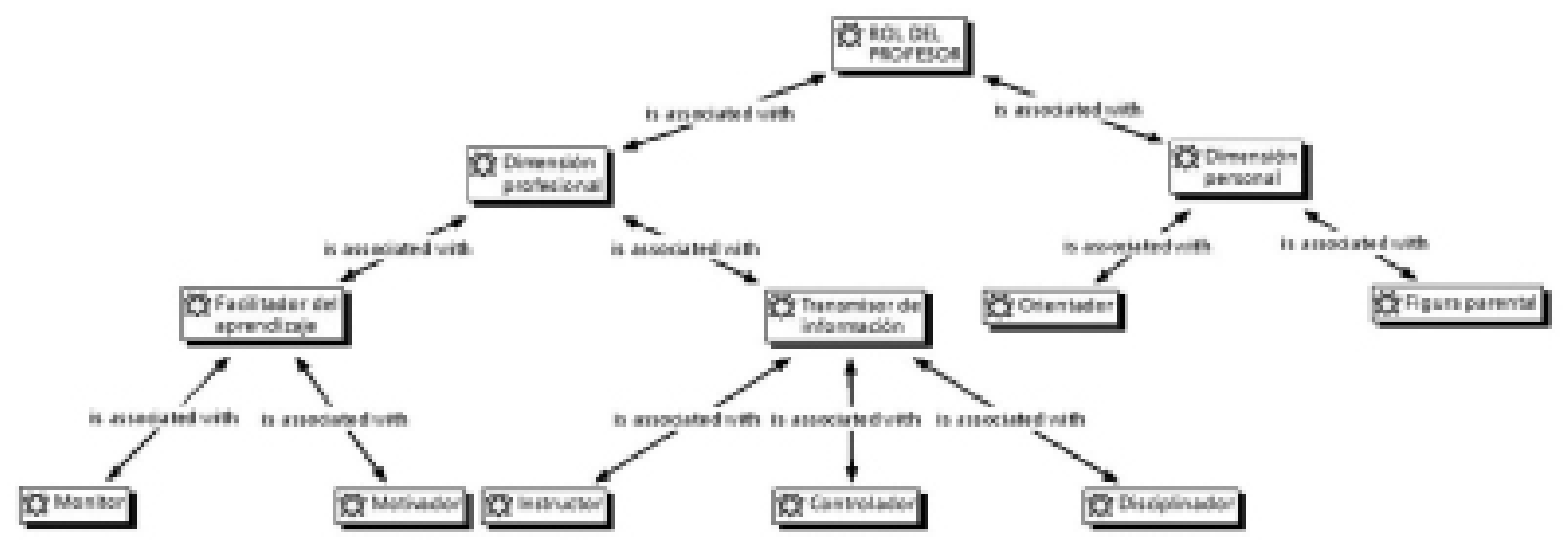

En el marco de la red conceptual relacionada con las creencias que poseen los futuros docentes sobre el rol del profesor de inglés es posible identificar como primera subcategoría una dimensión profesional, la cual se encuentra directamente ligada con el ejercicio docente. En este contexto, cuando los participantes son consultados sobre las acciones que deben llevar a cabo en el aula, algunos señalan que una de sus funciones corresponde a ser un facilitador del aprendizaje. Relativo a lo anterior, un docente en formación señala: "Creo que el profesor debería actuar como un mediador y facilitador del aprendizaje, ayudando a los alumnos a comprender el lenguaje dentro de un contexto" (E14 [06:06]). Asimismo, otro de los entrevistados parece poseer una perspectiva similar: "Para que los estudiantes pudiesen leer el texto en inglés, yo los guié, facilitándoles ejemplos sobre las palabras que ellos desconocían. Realicé esto para que ellos cumpliesen con los objetivos de la clase" (E08 [44:44]). Desde este punto de vista, los sujetos asocian el rol del profesor con el de un agente que promueve y guía la construcción de aprendizajes por parte de los estudiantes en el área de especialidad.

En el marco de las representaciones de los futuros docentes, las cuales permiten percibir al profesor de inglés como un facilitador en el proceso de aprendizaje, ellos también manifiestan que esta función sería desempeñada al ejercer el rol de monitor en las sesiones de clase. Al respecto, un entrevistado plantea lo siguiente:
"Guié a los estudiantes, verificando lo que aprendieron durante la clase y confirmando que estaban alcanzando los objetivos que se establecieron" (E12 [50:50]). Lo anterior también lo ha manifiestado un informante al describir características de su desempeño en el aula: "Como los estudiantes tienden a estar conversando, puede que no comprendan del todo las instrucciones. Es por esto que me acerco a ellos para comprobar su progreso, comunicándoles en qué van bien o lo que deben hacer" (E02 [53:53]). En este contexto, en función del discurso oral de los docentes en formación, es posible identificar que el rol del profesor como monitor sería desempeñado para lograr que los estudiantes de la asignatura de inglés construyan aprendizajes, con acompañamiento y respaldo durante el proceso pedagógico.

Asociado al punto previo, las creencias sobre el rol del profesor que poseen los participantes sugieren que, cuando el docente actúa como un facilitador para ayudar a los estudiantes a desarrollar sus aprendizajes con respecto a la lengua inglesa, este, a su vez, debería actuar como un motivador. Lo anterior lo manifiesta uno de los informantes de la siguiente manera: "Los alumnos de Educación Media suelen preguntarse quiénes son ellos. Una forma de cautivarlos es hacerlos leer sus signos zodiacales en inglés y, luego, preguntarles si es que están de acuerdo con lo que leyeron o no" (E20 [19:19]). En la misma línea, otro entrevistado hace referencia a lo anterior al indicar cómo se sobrepone a las dificultades que presentan los actuales esce- 
narios educativos: "Los estudiantes suelen no estar interesados en la clase; por lo tanto, es necesario que uno también pueda captar su atención e incitarlos a realizar las actividades" (E14 [30:30]). En este sentido, es posible reconocer que las representaciones de los futuros docentes sobre la función del profesor estarían basadas en el uso de diversas estrategias pedagógicas destinadas a incentivar y favorecer la disposición de los estudiantes hacia el aprendizaje.

Desde otro punto de vista, algunos entrevistados sostienen que la dimensión profesional asociada al rol del profesor comprende la actuación del mismo como un transmisor de información. Esta perspectiva es ilustrada en el siguiente segmento de entrevista: "Para mí enseñar es transmitir algo que uno conoce a los estudiantes para que ellos puedan aprender" (E04 [14:14]). En este marco, uno de los futuros docentes da a conocer las acciones que implementó en la sesión de clase observada, las cuales también se asocian a esta visión: "Debía explicar las reglas gramaticales relacionadas con un tiempo verbal en inglés. Esto a mis estudiantes les cuesta mucho. Tengo que repetir la información muchas veces para que ellos puedan comprender los contenidos sobre gramática” (E10 [06:06]). En función de lo manifestado por los participantes de la investigación, algunos de ellos poseerían creencias que vincularían la enseñanza de una lengua extranjera con la entrega y exposición de información.

Respecto a las características docentes que involucran la transmisión de información, algunos de los participantes aluden a que las mismas permiten reconocer al profesor de inglés como un instructor. En relación con este rol, un entrevistado manifiesta: "Más que guiarlos, yo les daba las instrucciones sobre lo que tenían que hacer [se refiere a los estudiantes del sistema educativo]" (E07 [28:28]). En este contexto, otro de los participantes señala haber llevado a cabo una función similar en la clase implementada: "Mi rol consistió, principalmente, en proveer directrices sobre las actividades de la clase. Puse énfasis en dar instrucciones porque es importante que los estudiantes las comprendan" (E01 [16:16]). Las creencias de los entrevistados sobre este rol se asociarían con el empleo de indicaciones con respecto a cómo los estudiantes deben desarrollar procedimientos y actividades en una sesión de clase.
Creencias sobre los roles del profesor y del estudiante que poseen futuros docentes de inglés en dos universidades chilenas Tania Tagle Ochoa / Claudio Díaz Larenas / Paola Alarcón Hernández / Lucía Ramos Leiva / Marcela Quintana Lara / Paulo Etchegaray Pezo

Adicionalmente, los futuros docentes parecen manifestar creencias asociadas al rol del profesor como un controlador en la sala de clases. Al respecto, un participante declara lo siguiente al ser consultado sobre las acciones que debería llevar a cabo considerando su actuar en el aula: "Verificando que estén haciendo lo que deben hacer y también vigilándolos [se refiere a los estudiantes del sistema educativo]" (E11 [43:43]). Asimismo, otro de los entrevistados declara también haber desempeñado esta función: "Recorría constantemente la sala de clases. De esa forma, me aseguraba que los estudiantes estuviesen concentrados en las tareas correspondientes" (E15 [41:41]). En este sentido, de acuerdo a lo señalado por los futuros docentes, el rol previamente identificado surgiría con el propósito de dirigir cómo los estudiantes intervienen en las actividades de aprendizaje, buscando, principalmente, dominar determinadas conductas por parte de los aprendices.

Asociado al rol del profesor como un transmisor de información, algunos de los docentes en formación consideran haber desempeñado la función de disciplinador. $\mathrm{Al}$ respecto, un participante señala lo siguiente cuando es consultado sobre las acciones que predominan en su actuar docente: "Siempre se nos va la clase en esto de que siéntate, que párate, que responde, que no hagas esto, que cumple las reglas, que no hablen, que escribe" (E09 [38:38]). En la misma línea, otro entrevistado hace alusión a cómo enfrentó determinados problemas experimentados en el aula: "Ellos [se refiere a los estudiantes del sistema educacional] saben que por cada minuto de clase que me hacen perder, yo les quitaré un minuto de su recreo" (E21 [55:55]). Considerando lo planteado por los futuros docentes, este rol emergería como una forma de lidiar o anticiparse a conductas disruptivas de los estudiantes.

En el contexto de la segunda subcategoría, las creencias de los futuros docentes ligadas al rol del profesor se asocian también con una dimensión personal. Desde este punto de vista, los participantes perciben al profesor como un orientador, el cual busca asesorar y respaldar a los estudiantes desde una perspectiva afectiva. Relativo a esto, un entrevistado señala: "Un profesor de inglés cumple muchos roles en el colegio y más aún si está 
comprometido con sus estudiantes... escuchar a los alumnos, prestarles atención, ser su amigo en el sentido de apoyarlos, socorrerlos y dar consejos" (E23 [62:62]). En este contexto, otro de los participantes alude también a la importancia de desempeñar este rol: "Es deber del profesor, además de enseñar inglés, orientar a los estudiantes. Es necesario ayudarlos y escucharlos porque ellos tienen confianza en uno" (E05 [72:72]). En función de esta visión, las creencias sobre el rol del profesor que poseen los futuros docentes parecen también basarse en la consideración del plano afectivo en el proceso pedagógico, ya que apoyan a los aprendices en el desarrollo de esta dimensión de la persona.

Por su parte, en lo relacionado con las creencias sobre el rol del profesor desde una dimensión personal, otros entrevistados reconocen también que el docente debería actuar como una figura parental. Asociado a lo anterior, un participante manifiesta lo siguiente al hacer referencia a la función que debería ejercer un docente de inglés: "Remplazar al papá y la mamá, actuando como ejemplos y comprendiendo a los estudiantes" (E24 [69:69]). De la misma forma, otro de los informantes, al hacer referencia a las obligaciones de un profesional de la educación, señala: "Los profesores deben no tan sólo enseñar los conocimientos relacionados con la asignatura. Es necesario, además, que ellos promuevan valores, tales como el respeto mutuo, puntualidad, como suele hacerlo un padre o una madre" (E19 [14:14]). En este sentido, es posible afirmar que las representaciones que poseen los futuros docentes se asocian a que el profesor debe desempeñarse como un adulto significativo en la vida de los estudiantes, desempeñando un rol relevante en su formación en valores.

En términos generales, los resultados presentados parecen indicar que las creencias de los participantes sobre el rol del profesor se articulan en un plano profesional y personal. Respecto al plano profesional, las representaciones identificadas en el discurso oral de los entrevistados se encontrarían orientadas en dos direcciones: por un lado, se percibe al profesional de la educación como un agente encargado de generar las condiciones necesarias para que los estudiantes construyan sus propios conocimientos. Por otro lado, se considera que el docente debe actuar como expositor de información para que los aprendices la repliquen y reproduzcan de forma correcta. En este marco, el hecho de que las creencias de los futuros docentes funcionen desde dos visiones distintas parece también evidenciarse en los hallazgos asociados a la siguiente unidad de análisis.

\section{Creencias sobre el rol del estudiante}

La categoría "creencias sobre el rol del estudiante", presentada a través de una red conceptual (véase la figura 2), permite identificar las siguientes subcategorías: constructor de conocimientos y receptor de información.

Figura 2. Red conceptual asociada a creencias sobre el rol del estudiante

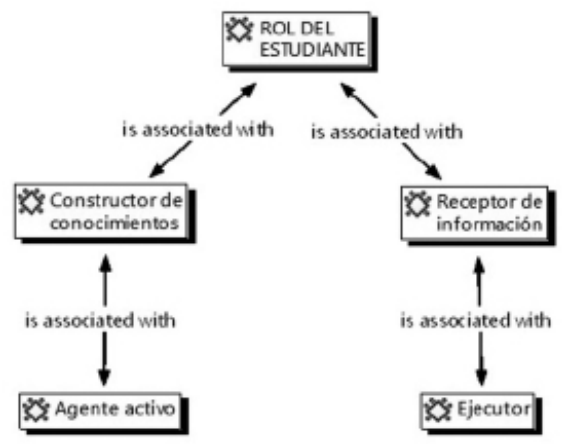

En el contexto de la red conceptual que hace referencia a las creencias que poseen los docentes en formación sobre el rol del estudiante, se presenta constructor de conocimientos como primera subcategoría. En este sentido, cuando se consulta a los entrevistados sobre las acciones que deben llevar a cabo los estudiantes en una clase de inglés, ellos señalan que la función de los mismos es generar acciones para favorecer la construcción de saberes. Lo anterior se evidencia a través del discurso oral de uno de los participantes: "Los estudiantes deben desarrollar su propio aprendizaje, averiguando y participando. Yo pocas veces doy las respuestas a las preguntas que me hacen; prefiero usar mímicas o dar pistas para que establezcan relaciones" (E12 [14:14]). En la misma línea, otro de los entrevistados parece indicar un punto de vista similar: "Para que cumplan los objetivos de la clase, ellos [se refiere a los estudiantes del sistema educacional] deben pensar y llegar a conclusiones por sus propios medios" (E08 [48:48]). En función del discurso oral de los futuros docentes, las representaciones que ellos poseen asignarían al estudiante un rol protagónico en el proceso pedagógico. 
Asociado a la visión previamente presentada, al ser consultados sobre cómo los estudiantes aprenden, algunos participantes estipulan que los mismos deberían asumir el rol de un agente activo. En este contexto, un entrevistado manifiesta lo siguiente al referirse a una actividad que suele realizar en las sesiones de clase que implementa: "Para que los alumnos aprendan a comunicarse en inglés, yo utilizo mucho la actividad de role-playing [se refiere a representación de roles y situaciones]. Cuando realizan eso, ellos deben crear y escribir diálogos para que, luego, los presenten oralmente" (E24 [34:34]). Asimismo, uno de los informantes, cuando hace alusión al rol asumido por los estudiantes del sistema educacional, señala que: "Los alumnos deben ser capaces de utilizar el idioma extranjero para comunicarse, además de realizar actividades por sí solos" (E17 [06:06]). De acuerdo a lo planteado por los docentes en formación, sus creencias sobre la enseñanza y el aprendizaje del idioma inglés se asociarían, principalmente, al uso funcional de la lengua extranjera, por parte de los aprendices, en el marco de procesos de comunicación.

Las creencias con respecto al rol del estudiante que poseen los futuros profesores se relacionan también con percibir al mismo como un receptor de información. Lo anterior se ve reflejado en el siguiente segmento de entrevista: "El rol del estudiante es sólo poner atención a la profesora y obedecer sus órdenes" (E22 [69:69]). En este contexto, al hacer referencia al desempeño de los aprendices en la clase observada, otro de los entrevistados plantea: "Los estudiantes sólo debían comprender reglas que presenté para usar los pronombres en inglés" (E03 [06:06]). Desde esta perspectiva, este tipo de prácticas, y las creencias que subyacen a las mismas, sugerirían que la función del estudiante sería actuar, exclusivamente, como un simple auditor considerando lo expuesto por el docente en una clase de inglés.

Relacionado con lo anterior, las representaciones de los futuros docentes que vinculan la enseñanza de la lengua extranjera con la entrega de información permiten reconocer al estudiante como un ejecutor de actividades. En este marco, un entrevistado estipula lo siguiente al dar a conocer la función de los estudiantes en ciertas tareas: "Se expuso el patrón afirmativo y negativo en presente simple, como estaba escrito en la guía... ellos tenían que seguirlo y, luego, escribirlo" (E06 [17:17]). De forma similar, uno de los informantes, cuando hace referencia a sus prácticas pedagógicas, declara: "Yo trato de hacer que entiendan en qué consiste cada contenido gramatical o de vocabulario, cómo se estructuran y para qué... uno presenta información y ellos la repiten simplemente" (E13 [02:02]). Al respecto, es posible inferir que las creencias que poseen algunos de los docentes en formación con respecto al rol del estudiante se relacionarían con la repetición o reproducción de modelos correctos del idioma extranjero. Esta visión predominaría, especialmente, en actividades basadas en la enseñanza de contenidos lingüísticos asociados a ítems léxicos o gramaticales.

En síntesis, las creencias que poseen los informantes de la investigación sobre el rol del estudiante se asocian a dos orientaciones sobre el proceso pedagógico: por un lado, se plantea que el estudiante debería tener un rol protagónico en el proceso de enseñanza y aprendizaje, usando la lengua extranjera de forma funcional y participando activamente en situaciones comunicativas y, por otro lado, debería cumplir la función de receptor de contenidos lingüísticos (principalmente gramática y vocabulario) que se requieren repetir o reproducir.

\section{Discusión}

Los futuros docentes de la carrera Pedagogía en Inglés participantes en este estudio parecen poseer creencias sobre el rol del profesor, las cuales asocian al mismo con un agente facilitador del aprendizaje y con un transmisor de información.

Respecto de las creencias de los entrevistados que relacionan al profesor de inglés con un facilitador del proceso de enseñanza y aprendizaje, estas sugieren que el docente debe ayudar a los estudiantes en la asignatura de inglés, guiándolos en la construcción de sus propios aprendizajes. Desde la perspectiva de los participantes del estudio, la función señalada involucraría que el docente ejerza el rol de monitor, acompañando a los estudiantes y apoyándolos oportunamente en función de dificultades que pudiesen experimentar en el aprendizaje. Asimismo, los 
docentes en formación entrevistados estipulan que, cuando el profesor asume el rol de facilitador en el proceso de enseñanza y aprendizaje, requiere generar condiciones para que los estudiantes se sientan motivados a aprender.

Relativo a lo expuesto, las creencias de los entrevistados que vinculan el rol del profesor con un facilitador que recurre a procedimientos que involucran monitoreo y motivación para generar aprendizajes se encontrarían ligadas a una visión constructivista de la enseñanza. Estas representaciones se relacionarían con guiar al estudiante a construir conocimientos y significados asociados principalmente al desarrollo de habilidades (Lin, Shein y Yang, 2012; Poom-Valickis, Oder y Lepik, 2012).

Desde otro punto de vista, las creencias de los futuros docentes permiten también identificar al profesor como un transmisor de información. Asociado a esta representación, el profesional de la educación buscaría que los estudiantes aprendan, instruyendo, vigilándolos y disciplinándolos cuando sea necesario. Estas prácticas se implementarían para asegurarse de que ellos lleven a cabo las acciones establecidas, buscando reforzar o evitar conductas por medio de la sanción y la administración de recompensas. Al respecto, la representación sobre el rol del profesor expuesta con anterioridad estaría relacionada con una propuesta de enseñanza y aprendizaje tradicionalista. Esta concepción vincularía el aprendizaje con la formación de hábitos, más que con lograr que los estudiantes consideren mecanismos para autogestionar su proceso de construcción de conocimientos o autorregular su comportamiento (Ertmer y Newby, 2013).

Las creencias de los futuros docentes sobre el rol del profesor también permiten identificarlo como una figura parental que brindaría a los estudiantes orientación, protección y auxilio desde una perspectiva afectiva. Desde el punto de vista de los docentes en formación, el desempeñarse considerando aspectos propios de esta dimensión desencadenaría en que el profesor funcionara también como un formador de valores. En este contexto, las creencias de los participantes se relacionan con promover, además de aprendizajes propios de la asignatura, principios que permitan orientar las conductas y actitudes de los estudiantes del sistema educacional.
$\mathrm{Al}$ respecto, puede resultar positivo que los estudiantes de Pedagogía en Inglés entrevistados señalen que, para satisfacer las demandas del actual contexto educacional, su deber es ejercer una variedad de funciones, incluso aquellas propias de un progenitor; sin embargo, al no cumplir con las expectativas asignadas a este rol podrían, eventualmente, sufrir determinados niveles de angustia, ansiedad o incertidumbre al no sentirse satisfechos con su desempeño profesional e inserción en el campo laboral (Castle y Buckler, 2009). Esto, a su vez, podría conllevar a que los futuros docentes pudiesen ser incapaces de encontrar soluciones a dificultades encontradas en su práctica profesional (Merç, 2011). En este contexto, se sugiere que los programas de formación, además de favorecer el desarrollo de competencias pedagógicas y disciplinarias, también consideren y fortalezcan los procesos de desarrollo personal de los futuros profesores (Pelton, 2014).

Los resultados de este estudio se condicen con las tendencias actuales sobre los modelos didácticos para la formación de profesores de inglés, por cuanto nos encontramos en una etapa post-modelos, en la cual los futuros docentes de inglés y los profesores en ejercicio integran creencias y prácticas pedagógicas provenientes de diversos referentes didácticos (Taggart y Wilson, 2005), que más bien se ajustan, según la naturaleza de los estilos de aprendizaje de sus propios estudiantes, al contexto donde se desempeñan. Prueba de ello es la variedad de roles que asume un profesor en su práctica pedagógica. Algunos de estos roles tienen una naturaleza más tradicional y centrada en la transmisión de contenidos, como es el caso del rol controlador al que aluden los participantes; otros roles poseen un corte más comunicativo y centrados en el aprendizaje de los estudiantes, como es el caso del rol facilitador.

Por otro lado, los profesores en formación de la carrera de Pedagogía en Inglés participantes en este estudio parecen poseer creencias sobre el rol del estudiante, que lo relacionan con un constructor de su propio proceso de aprendizaje y con ser un receptor de información.

La primera visión plantea al estudiante como responsable de construir su propio conocimiento, actuando como un gestor del aprendizaje o agente activo. Esta representación estaría asociada, princi- 
palmente, a una concepción de enseñanza y aprendizaje constructivista. Al respecto, es posible señalar que la implementación de prácticas pedagógicas orientadas por una propuesta constructivista, en las cuales los estudiantes se desempeñen aprendiendo autónomamente, potenciarían la capacidad de los mismos para desarrollar habilidades cognitivas y metacognitivas, hecho que les permitiría solucionar, por sí mismos, problemas propios de su contexto $y$, a su vez, satisfacer necesidades de aprendizaje (Reinders y Balcikanli, 2011).

Desde una perspectiva opuesta, los entrevistados también establecen que la función del estudiante consiste en recibir la información expuesta por el docente para, luego, reproducir modelos por medio de la ejercitación. Esta visión se basaría en el rol del estudiante enmarcado en una propuesta de enseñanza tradicionalista, en la cual se aprendería el idioma a través de la repetición y segmentación del mismo (Phipps y Borg, 2009). La función de receptor de información que se le atribuiría al estudiante, en el contexto chileno, se debería a que las prácticas pedagógicas de los docentes no serían de carácter funcional, ni implicarían el uso directo de la lengua extranjera por parte de los aprendices (Díaz, Alarcón y Ortiz, 2012). Lo anterior, a su vez, no permitiría a los estudiantes desarrollar habilidades comunicativas en el idioma, y aprenderían principalmente aspectos del lenguaje aislados en función de la gramática o el vocabulario.

La permanencia de creencias tradicionales se puede deber a lo arraigadas que pueden estar las mismas producto de su permanencia en el tiempo (Mattheoudakis, 2007). Al respecto, se plantea que las representaciones que han sido adquiridas en experiencias educacionales tempranas suelen encontrarse profundamente enraizadas, siendo aquellas que han sido almacenadas por mayor tiempo en la memoria a largo plazo las más difíciles de reestructurar (Farrell, 2009; Özmen, 2012). La razón de lo anterior podría ser que estas se encuentran alojadas en lo más profundo de los sistemas que las conectan y las relacionan entre sí. Por consiguiente, las creencias asociadas a los roles del estudiante y del profesor podrían invisibilizarse si no se cuestionan continuamente .
Creencias sobre los roles del profesor y del estudiante que poseen futuros docentes de inglés en dos universidades chilenas Tania Tagle 0choa / Claudio Díaz Larenas / Paola Alarcón Hernández / Lucía Ramos Leiva / Marcela Quintana Lara / Paulo Etchegaray Pezo

Por otro lado, la permanencia de creencias tradicionalistas puede asociarse a las características del sistema escolar en el cual se desempeñan los docentes en formación. En este marco, se sugiere que cuando los estudiantes de pedagogía perciben que las innovaciones implementadas tienen un impacto negativo en la realidad en que se desempeñan, tenderán a ceder ante prácticas que se encuentran implícitamente establecidas en ese contexto (Erkmen, 2014).

\section{Conclusiones}

Con respecto a los antecedentes expuestos de forma previa, es posible señalar que los participantes de esta investigación poseen creencias sobre los roles del profesor y del estudiante, las cuales se enmarcan en una propuesta de enseñanza y aprendizaje constructivista y también en una tradicional, lo que reflejaría la existencia de modelos didácticos que no se manifiestan de manera ortodoxa a nivel de creencias y desempeños docentes sino que, más bien, los participantes integran los aportes de cada modelo para representar el proceso de enseñanza y aprendizaje con todas sus complejidades y desafíos en términos de creencias que se van conformando, según los requerimientos de aprendizaje de los estudiantes, y las dificultades y obstáculos de los contextos en que se desempeñan.

La permanencia de creencias tradicionalistas puede deberse a lo profundamente arraigadas que estén las mismas producto de lo temprano de su construcción en el sistema escolar o porque el contexto educativo puede estar reforzando positivamente la perpetuación de prácticas pedagógicas tradicionales. Al respecto, se requiere que los programas de formación inicial de docentes continúen desarrollando iniciativas a nivel de la línea de práctica que incentiven a los estudiantes a reflexionar en su desempeño profesional considerando el impacto del mismo en el proceso de aprendizaje de los estudiantes del sistema escolar. Por su parte, la aparición de creencias de corte más constructivista podría ser reflejo de los procesos de rediseño curricular en los que se ha embarcado la formación de profesores de inglés en Chile, de tal forma de movilizarse desde 
modelos de formación fuertemente enraizados en la transmisión de información a modelos formativos que relevan el desarrollo de competencias y visibilizan los resultados de aprendizaje de los estudiantes y los tiempos que ellos requieren para su desarrollo.

Por otro lado, pareciese ser positivo el hecho de que los futuros docentes, más allá de ser especialistas con respecto a los contenidos de la asignatura, se vean a sí mismos como agentes responsables en el marco de una dimensión personal y afectiva. No obstante, cumplir una diversidad de funciones que, a veces, sobrepasan las labores de un profesional de la educación, podría causar frustración e inseguridad. Al respecto, se sugiere que los programas de formación consideren profundamente el desarrollo de la dimensión afectiva en el proceso de preparación profesional de los docentes para facilitar que los mismos enfrenten las demandas que el sistema educacional les plantea en su rol como formadores. Cobra mucho sentido poner énfasis en la dimensión afectiva del aprendizaje de una segunda lengua, en la medida en que aprender un segundo idioma constituye un proceso personal altamente complejo, que involucra al ser humano en sus dimensiones cognitiva, afectiva y social.

Finalmente, en función del estudio desarrollado es relevante mencionar que, como se ha planteado en este artículo, las creencias sobre la propia práctica pedagógica suelen ser invisibles a la conciencia; por lo tanto, cuando un docente intenta modificarlas, le es muy complejo articular y estructurar sus representaciones. Cabe destacar que en esta investigación fue posible identificar y examinar las creencias que los participantes poseían sobre el rol del profesor y del estudiante por medio de la entrevista con recuerdo estimulado. Hacer preguntas a los sujetos de estudio, exponiéndoles segmentos de video sobre su desempeño pedagógico fue una herramienta útil para favorecer los procesos de reflexión. A pesar de que la implementación de esta técnica pudiese tomar tiempo, la misma puede ser incorporada en la línea de práctica de programas de formación profesional para ayudar a los futuros docentes a identificar sus representaciones sobre los procesos de enseñanza y aprendizaje y, por consiguiente, generar acciones para su cambio o reestructuración en caso de que estas se encuentren ligadas a prácticas tradicionalistas.

\section{Referencias bibliográficas}

Alarcón, P.; Díaz, C.; Tagle, T.; Ramos, L. y Quintana, M. (2014). Metáforas para profesor y estudiante de pedagogía, en un grupo de estudiantes de pedagogía chilenos. Actualidades Investigativas en Educación, 14(2), 1-31.

Arends, R. I. y Kilcher, A. (2010). Teaching for student learning: Becoming an accomplished teacher. Nueva York, NY: Routledge.

Ausubel, D. P. (2002). Adquisición y retención del conocimiento: una perspectiva cognitiva. Barcelona: Paidós.

Blázquez, F. y Tagle, T. (2010). Formación docente: Un estudio de las creencias de alumnos y profesores sobre el proceso de enseñanza y aprendizaje del inglés. Revista Iberoamericana de Educación, 54(4), $1-12$.

Castle, P. y Buckler, S. (2009). How to be a successful teacher: Strategies for personal and professional development. Londres: Sage.

Coll, C. (1990). Aprendizaje escolar y construcción del conocimiento. Barcelona: Paidós.

Coll, C.; Onrubia, J. y Mauri, T. (2008). Ayudar a aprender en contextos educativos: el ejercicio de la influencia educativa y el análisis de la enseñanza. Revista de Educación, 346, 33-70.

Díaz, C. y Solar, M. I. (2011). La revelación de las creencias lingüístico-pedagógicas a partir del discurso del profesor de inglés universitario. RLA, Revista de Lingüística Teórica y Aplicada, 49(2), 57-86.

Díaz, C.; Alarcón, P. y Ortiz, M. (2012). El profesor de inglés: sus creencias sobre la evaluación de la lengua inglesa en los niveles primario, secundario y terciario. Íkala, Revista de Lenguaje y Cultura, 17(1), 15-26.

Díaz, C.; Martínez, P.; Roa, I. y Sanhueza, M. G. (2010). Los docentes en la sociedad actual: sus creencias y cogniciones pedagógicas respecto al proceso didáctico. Polis, Revista de la Universidad Bolivariana, 9(25), 421-436.

Erkmen, B. (2014). Novice EFL teachers' beliefs about teaching and learning, and their classroom practices. H. U. Journal of Education, 29(1), 99-113.

Ertmer, P. A. y Newby, T. J. (2013). Behaviorism, cognitivism, constructivism: Comparing critical features from an instructional design perspective. Performance Improvement Quarterly, 26(2), 43-71.

Falsafi, L. y Coll, C. (2011). La construcción de la identidad de aprendiz: coordenadas espacio-temporales. 
En C. Monereo y J. I. Pozo (eds.), La identidad en psicología de la educación: necesidad, utilidad y límites (pp. 77-98). Madrid: Narcea.

Farrell, T. S. C. (2009). Critical reflection in a TESL course: Mapping conceptual change. ELT Journal, 63(3), 221-229.

Gass, S. M. y Mackey, A. (2000). Stimulated recall methodology in second language research. Mahwah, NJ: Lawrence Erlbaum.

Gómez, V. y Guerra, P. (2012). Teorías implícitas respecto a la enseñanza y el aprendizaje: $¿$ Existen diferencias entre profesores en ejercicio y estudiantes de pedagogía? Estudios Pedagógicos, 38(1), 25-43.

Larsen-Freeman, D. y Anderson, M. (2011). Techniques and principles in language teaching ( $3{ }^{\mathrm{a}} \mathrm{ed}$.). Oxford: Oxford University Press.

Levin, B. y He, Y. (2008). Investigating the content and sources of teacher candidates' personal practical theories (PPTs). Journal of Teacher Education, 59(1), 55-68.

Levin, T. y Wadmany, R. (2006). Teachers' beliefs and practices in technology-based classrooms: A developmental view. Journal of Research on Technology in Education, 39(2), 157-181.

Lin, W. C., Shein, P. P. y Yang, S. C. (2012). Exploring personal EFL teaching metaphors in pre-service teacher education. English Teaching: Practice and Critique, 11(1), 183-199.

Lippman, P. C. (2010). Evidence-based design of elementary and secondary schools: A responsive approach to creating learning environments. Hoboken, NJ: John Wiley \& Sons.

Malderez, A. y Bodóczky, C. (2002). Mentor courses: A resource book for trainer-trainers. Cambridge: Cambridge University Press.

Mattheoudakis, M. (2007). Tracking changes in preservice EFL teacher beliefs in Greece: A longitudinal study. Teaching and Teacher Education, 23(8), 1272-1288.

Merç, A. (2011). Sources of foreign language student teacher anxiety: A qualitative inquiry. Turkish Online Journal of Qualitative Inquiry, 2(4), 80-94.

Nilson, L. B. (2010). Teaching at its best: A research-based resource for college instructors (3. ${ }^{\mathrm{a}}$ ed.). San Francisco, CA: Jossey-Bass.
Creencias sobre los roles del profesor y del estudiante que poseen futuros docentes de inglés en dos universidades chilenas

Tania Tagle Ochoa / Claudio Díaz Larenas / Paola Alarcón Hernández / Lucía Ramos Leiva / Marcela Quintana Lara / Paulo Etchegaray Pezo

Özmen, K. S. (2012). Exploring student teachers' beliefs about language learning and teaching: A longitudinal study. Current Issues in Education, 15(1), 1-16.

Pagliaro, M. M. (2011). Educator or bully: Managing the 21st-century classroom. Plymouth: Rowman \& Littlefield Education.

Pelton, J. A. (2014). Assessing graduate teacher training programs: Can a teaching seminar reduce anxiety and increase confidence? Teaching Sociology, 42(1), 40-49.

Phipps, S. y Borg, S. (2009). Exploring tensions between teachers' grammar teaching beliefs and practices. System, 37(3), 380-390.

Poom-Valickis, K.; Oder, T. y Lepik, M. (2012). Teachers' beliefs regarding their professional role: A gardener, lighthouse or circus director? Procedia-Social and Behavioral Sciences, 69, 233-241.

Reinders, H. y Balcikanli, C. (2011). Learning to foster autonomy: The role of teacher education materials. Studies in Self-Access Learning Journal, 2(1), 15-25.

Richards, J. C. (2006). Communicative language teaching today. Nueva York, NY: Cambridge University Press.

Richards, J. C. y Rodgers, T. S. (2014). Approaches and methods in language teaching (3. $\left.{ }^{\mathrm{a}} \mathrm{ed}.\right)$. Cambridge: Cambridge University Press.

Saban, A. (2004). Prospective classroom teachers' metaphorical images of selves and comparing them to those they have of their elementary and cooperating teachers. International Journal of Educational Development, 24(6), 617-635.

Taggart, G. L. y Wilson, A. P. (2005). Promoting reflective thinking in teachers: 50 action strategies ( $2 .^{\mathrm{a}}$ ed.). Thousand Oaks, CA: Corwin Press.

Tagle, T.; Díaz, C.; Alarcón, P.; Quintana, M. y Ramos, L. (2014). Creencias de estudiantes de pedagogía sobre la enseñanza del inglés. Folios, 39, 77-87.

Thomas, L. y Beauchamp, C. (2011). Understanding new teachers' professional identities through metaphor. Teaching and Teacher Education, 27(4), 762-769.

Wheeler, G. (2013). Language teaching through the ages. Nueva York, NY: Routledge.

Williams, M. y Burden, R. L. (2001). Psychology for language teachers: A social constructivist approach. Cambridge: Cambridge University Press.

Wright, T. (2010). Second language teacher education: Review of recent research on practice. Language Teaching, 43(3), 259-296. 
Universidad Pedagógica Nacional

Facultad de Humanidades

\section{Anexo 1: Protocolo para entrevista semiestructurada}

¿Qué significa para usted enseñar?

¿Cómo se enseña inglés?

¿Qué significa para usted aprender?

¿Cómo se aprende inglés?

¿Cómo se enseña a hablar en inglés?

¿Cómo se aprende a hablar en inglés?

¿Cómo se enseña a escribir en inglés?

¿Cómo se aprende escribir en inglés?

¿Cómo se enseña a comprender textos hablados en inglés?

¿Cómo se aprende a comprender textos hablados en inglés?

¿Cómo se enseña a comprender textos escritos en inglés?

¿Cómo se aprende a comprender textos escritos en inglés?

¿Qué rol(es) debe asumir un profesor en una clase de inglés?

¿Qué rol(es) debe asumir un estudiante en una clase de inglés? 